\title{
RESEARCH ARTICLE \\ Metagenomics approaches \\ in microbial ecology and research for sustainable agriculture
}

Robert Meunier, Institute of Philosophy, University of Kassel, Henschelstr.2, 34127 Kassel, DE (robert.meunier@uni-kassel.de) (D) 0000-0002-4026-6167 Saliha Bayır, Institute of Philosophy, University of Kassel, Kassel, DE (saliha.bayir@uni-kassel.de) (D) 0000-0002-8105-0215

Abstract - Technologies such as next generation sequencing (NGS) are transforming research fields at the methodological, conceptual, and organizational level. They open up new possibilities and bring with them new commitments and inherent limitations. We show from a philosophy of science perspective how NGS-based metagenomics has transformed microbial ecology and, with it, parts of agricultural soil science, which integrate ecological approaches with the aim to inform agricultural practices. We reconstruct agricultural science as design science (sensu Niiniluoto) and describe how the possibilities, commitments, and limitations of metagenomics approaches in microbial ecology shape values, situation assessments, and recommendations for interventions of soil microbiology in the context of sustainable agriculture.

\section{Metagenomische Ansätze in der mikrobiellen Ökologie und Forschung für nachhaltige Landwirtschaft}

Zusammenfassung - Technologien wie Next Generation Sequencing (NGS) transformieren Forschungsfelder auf der methodischen, konzeptionellen und organisatorischen Ebene. Sie eröffnen neue Möglichkeiten, bringen aber auch neue Festlegungen und inhärente Beschränkungen mit sich. Wir zeigen aus wissenschaftsphilosophischer Perspektive wie NGS-basierte Metagenomik die mikrobielle Ökologie und damit auch Teile der agrarwissenschaftlichen Bodenforschung transformiert hat, die ökologische Ansätze integrieren, um landwirtschaftliche Praktiken zu verändern. Wir rekonstruieren die Agrarwissenschaft als Designwissenschaft (sensu Niiniluoto) und beschreiben, wie die Möglichkeiten, Festlegungen und Beschränkungen der metagenomischen Ansätze in der mikrobiellen Ökologie die Werte, Situationsbewertungen und Empfehlungen für Eingriffe der Bodenmikrobiologie im Kontext nachhaltiger Landwirtschaft beeinflussen.

This is an article distributed under the terms of the Creative Commons Attribution License CCBY 4.0 (https://creativecommons.org/licenses/by/4.0/) https://doi.org/10.14512/tatup.30.2.24

Received: Feb. 05, 2021; revised version accepted: May 17, 2021;

published online: Jul. 26, 2021 (non-blind peer review)
Keywords - basic vs. applied science, metagenomics, microbial ecology, sustainable agriculture

\section{Introduction}

A metagenomics approach consist in the sampling of genomic material directly from a selected environment. It can capture a whole ecological community in a given environment such as a patch of soil by means of its collective genomic content. This approach, which became possible through next generation sequencing (NGS), is now widely applied in agricultural soil research. The latter is generally viewed as an applied science, aiming to improve agricultural practice. The common distinction between basic and applied science is as useful as it is problematic. Much of the difficulty results from the ambiguity of the notion of science involved, as it can refer to institutionalized disciplines as much as to research practices or results. Furthermore, applied science needs to be distinguished from the scientifically informed contexts of application.

In this paper, we adopt a framework suggested by Ilkka Niiniluoto (1993) and construe individual projects within a given science, in our case soil microbial ecology, as basic or design science, respectively, depending on whether the outcome is descriptive or consists in recommendations for interventions, regardless of the disciplinary affiliations of researchers involved. Basic science projects can be motivated by or funded for their potential to produce knowledge relevant for other fields of human practice. But this alone does not turn them into design science if they do not deliver recommendations. In such cases, one might want to speak of 'use-inspired basic research' (Stokes 1997). Basic and design science projects can be pursued in classical university research settings as well as in non-academic or combined 'Mode 2' science settings (Gibbons et al. 1994). Niiniluoto's classificatory schema allows us to track how metagenomics approaches in basic science projects, aimed at developing novel descriptions and 
theoretical perspectives regarding soil microbial communities, re-orients the outlook of the respective design science projects delivering recommendations informing agricultural contexts.

\section{The translation of approaches from basic to design science projects}

Niiniluoto defines design science as "research aiming at knowledge that is useful for the activity of design", where design "in the broad sense includes all 'artificial' human activities, i. e., the production, preparation, or manipulation of natural systems [...] or artefacts" (Niiniluoto 1993, p. 8). Agricultural science is among Niiniluoto's examples of design science. The relevant profession is the farmer, the practice is agriculture, the skill involved is the art of farming. Such human practices underwent processes of mechanization, i. e., the development of tools, as well as scientification, i. e., the development systematic bodies of rules. Design science supports both these developments and results in what Niiniluoto calls 'technical norms' (not to be confused with technical standards), defined as statements relating means and ends of the form 'If you want A, and you believe that you are in a situation B, then you ought to do X'. Such statements, unlike the descriptive statements of basic science, are clearly normative. Whether or not one adopts Niiniluoto's establishing new ontologies, and thus pre-configuring the discursive universe in which design science recommendations are formulated. Alternative approaches could make the phenomena in question accessible in a different manner, thus resulting in different recommendations. We thus depart from Niiniluoto's view by emphasizing the pluralistic and perspectival nature of the results of basic science. Such a view, however, is not incompatible with realism and the notion that science delivers true statements about the world (Massimi 2018).

As the purpose of applying Niiniluoto's framework is to distinguish projects with descriptive and normative outcomes in order to reconstruct their interrelation, and to analyze the aspects of values and goals, situation assessments, and interventions characterizing design science projects, issues of realism need not be further discussed here. While we take these aspects on board, we complement Niiniluoto's account in a way that allows us to move beyond the focus on theoretical results emphasized by Niiniluoto as much as by perspectivists. According to these views, knowledge about phenomena in form of the respective representations constitutes a perspective or is transferred from basic to design science. We focus, instead, on the ways that research practices themselves are directional and selective in the way suggested by the metaphor of perspective for theoretical representations. The actor's category of an approach seems to express this fact: to approach an object implies to move to-

\section{We will show how basic science pre-configures the discursive universe in which design science recommendations are formulated.}

view that their truth value "is an 'objective' and general feature of the world" (Niiniluoto 1993, p. 12), it is clear that agents can agree on the validity of the statement even if they disagree whether the recommendation should be followed. As Niiniluoto points out, there can be disagreement regarding the values and associated goals, the actual state of the current situation, or the causal relations underlying an intervention. While the latter two issues can be addressed by empirical research, the former is subject to political debate. In any case, design science is justified when it is relevant, i.e., the situations expressed in its technical norms do obtain and the values inscribed in the goal in its antecedent are held by at least some group. Values and associated goals can result from public policy planning or attitudes of segments of civil society.

Regarding basic science, Niiniluoto holds a realist view. On his account, basic research delivers descriptive knowledge of causal regularities governing the relation of $\mathrm{A}, \mathrm{B}$ and $\mathrm{X}$ underlying the technical norms of design science. In the following, we will go beyond this analysis, by showing how basic science approaches make phenomena accessible in the first place, thereby wards it from a given direction and to access it in a particular way. On our account, an approach is embodied in an experimental system enabling specific and selective material and cognitive access to epistemic objects (Rheinberger 1997). Approaches are translated from basic to design science projects and with them theoretical perspectives. Pluralism then results from the co-existence of approaches.

To return to our case, metagenomics approaches were integrated in experimental systems in microbial ecology and provided access to different aspects of microbial life than earlier culture-based approaches and made them available for basic science descriptions in ecological and genomic terms. In addition to the descriptive knowledge, the approach that enabled such knowledge itself was translated by adapting it to design science projects in agricultural soil science. In this way, the latter inherited the new possibilities and inherent limitations for material access and cognitive and symbolic representation, which then shaped its technical norms.

In the next section, we will show how accessing microbial communities through their collective genomic material (metage- 
nome) re-oriented the conceptual representation of microbial life, from a focus on taxonomic groups (microbiota) and their phylogeny (i.e., evolutionary relationships) and physiology (i.e., their functions as a living system), to the study of integrated and interacting communities (microbiomes) and their structure and function, which were then mainly characterized on the level of genes and gene functions. ${ }^{1}$ Subsequently, we will indicate how agricultural soil science adopted these metagenomics approaches and with them the genome-centered representation of microbial life. This shaped the conceptualization of goals, situations, and interventions in terms of soil quality in relation to agricultural practices and thus the resulting technical norms that potentially inform policy makers, actors in agribusiness, and farmers.

\section{From microbial cultures to an ecology of genomes in microbial ecology}

Microbial ecology emerged from environmental microbiology as the study of the relationships of microorganisms with their environment and among each other. Due to the need for developing procedures for examining microbial life in its natural context and bringing to light life forms which are otherwise invisible, environmental microbiology was a technology-driven field since its inception at the beginning of the twentieth century. Soil and marine microbiology were crucial in the development of microbial ecology. The outlook of these fields differed significantly from those of medical microbiology and food production, which conceived of specific microbes as pathogens to be removed from bodies, or as reagents, respectively (O’Malley 2014). Soil micro- come the shortcomings of culturing techniques and characterize the biodiversity of environmental samples, researchers began to integrate molecular biology techniques. Following Frederick Sanger's development of a sequencing technique in 1977 and using the insight of Carl Woese and colleagues that highly conserved ribosomal ribonucleic acid (rRNA) subunits can be employed for phylogenetic characterization (Woese 1983), Norman Pace and colleagues began to adjust this molecular technique as a culture-independent approach for studying the biodiversity of naturally-occurring microbial communities, using environmental samples (Pace et al. 1986).

The early development of sequencing techniques thus offered a new way to access the complexity of microbial life. Molecular phylogenetic analysis and the conclusions drawn about species richness and abundance prompted the beginning of environmental metagenomics approaches. As a result of this change of research culture and ensuing possibilities of environmental microbiology to become more ecology-oriented and address microorganisms at the community level, microbial ecology established itself as a hybrid between ecology and microbiology (O'Malley 2014). ${ }^{2}$ As the field pushed the advancement and integration of sequencing methods, the development of NGS platforms around 2005 had a strong impact on microbial ecology. NGS allowed for massive parallel sequencing of millions of short reads (i.e., sequences of DNA or RNA strings of several hundred base pairs), as it decreased the time and costs of sequencing significantly (Slatko et al. 2018).

This had several consequences as researchers were now able to a) detect also viral particles and free DNA sequences; b) improve the description of community composition and phylogenetic relations (Pereira et al. 2017); and c) analyze and predict

\section{Metagenomics approaches generate a selective, genome-centered theoretical perspective on soil ecology.}

biologists, instead, considered the diversity of microbial components of soil as fundamental and as contributing to the richness of soil as substrate for plants. Therefore, the methods of soil microbiologists were developed in the context of or applied by agricultural sciences early on (Ackert 2007).

Environmental microbiologists were aware of a discrepancy between the types of viable cells in the cultured samples and the range of diversity observed with microscopes. In the late 1970s it became apparent that only $0,1-1 \%$ of microbial life from samples could be retrieved with available culturing techniques, a fact referred to as the "great plate count anomaly" (Staley and Konopka 1985; for recent criticism, see Martiny 2019). To over-

1 While the term 'microbiota' refers to all microbes in a given environment, 'microbiome' denotes microbial communities in a given habitat, their internal and external interactions, as well as their genomic content (Berg et al. 2020). community functions such as nitrogen or sulfur metabolism, respiration, motility, etc. (Fierer et al., 2012). Especially the latter point implies a new, systems-based understanding of microbial communities based on the analysis of the whole DNA content of a sample as it characterizes the new NGS-based metagenomics approaches. Analyzing the genes present in a community, the proteins they potentially encode, and the gene-transfer networks and metabolic pathways they form, gradually became more central to research agendas than identifying individual species, community structure, and phylogenetic relations (Gupta et al. 2019). The shift of emphasis from community structure to community functions resulted in a view of microbial communities as integrated functional units themselves rather than a

2 Ecological communities are composed of various species, which interact with each other in a given habitat. 
sum of individual organisms (Konopka 2009). But as indicated by the concept of the microbiome, these units are now mainly understood through their collective genome (Berg et al. 2020).

While we showed how NGS technologies enabled access to previously inaccessible dimensions of microbial life, we conclude that metagenomics approaches generated a genome-centered theoretical perspective on soil ecology. Despite our emphasis on the selective nature of these approaches and the resulting perspective on the biological dimension of soil, it is important to note that microbial ecologists typically employ different complementary strategies in addition to NGS. For instance, soil is submitted to chemical and physical characterizations (Fierer, 2017). Furthermore, microbial ecologists are aware of and address limitations of the approach: 1) Predicted community functions reflect only potential activity as many genes may originate from dormant cells or DNA debris and as genes are transcribed and translated into proteins only under certain environmental conditions (Prosser 2020). 2) Testing sequence-based predictions and gaining knowledge about cell-level anatomy and physiology, as well as modes of interaction among microbes and between microbes and plants would require culturing microorganisms in the lab. However, even though new culturing techniques are developed, various factors such as dormancy, symbiotic interdependency, low abundance, and competition still constitute difficulties for cultivation under lab conditions (Lewis et al. 2021). 3) Metagenomics results in massive amounts of data and the 'bioinformatics bottleneck' diagnosed for other fields employing NGS applies here as well (Desai et al. 2012). Filtering out information irrelevant for the pursued research question and analyzing and interpreting data requires special expertise (Kulkarni and Frommolt 2017). Therefore, collaboration with bioinformaticians becomes a necessary organizational feature of microbial ecology.

The next section addresses the fate of metagenomics approaches to soil microbiology in the context of agricultural science.

\section{The constituents of technical norms in research for sustainable agriculture}

Agricultural science is a multidisciplinary field producing knowledge about elements of agricultural practice on various levels, including soil, plants and pests, chemical and mechanical production technologies, and crop management strategies, as well as economic and political dimensions (Noll 2016). Many projects deliver descriptive knowledge on these aspects and can be categorized as use-inspired basic research. However, large parts of agricultural science aim at technical norms, i. e., recommendations about how to treat soil, choose or improve crops, handle pests, use technologies or design and implement policies. Such recommendations typically involve (methods for) the assessment of situations and are delivered under the assumption of a set of values and goals. Technical norms are derived by ap- plying knowledge and approaches of basic science to the assessment of situations and the identification of causal regularities suitable for interventions. The study of the microbial dimension of soil in agricultural science has been strongly enhanced by NGS technologies. In the following, we will briefly indicate how the adoption of metagenomics approaches from microbial ecology has shaped the articulation of values and goals, the assessment of situations, as well as the recommended interventions in the technical norms delivered by agricultural soil research.

\section{Values and Goals}

Since agricultural research became institutionalized in various national contexts in the latter half of the nineteenth century, increasing productivity was a central goal (Noll 2016). With an ever-increasing demand for food, feed, fiber, fuel and pharmaceuticals, many depict this goal as more urgent than ever. This goal is derived from the underlying, albeit promissory values of (global) prosperity and well-being. Detrimental effects of agricultural intensification such as ecosystem degradation and biodiversity loss led to a new agenda aimed at halting these processes, resulting in calls for sustainable agriculture (Thompson 2016). The role of science is then seen as mitigating these processes, either by developing alternative strategies, or by delivering technological fixes (Puig de la Bellacasa 2015). In some of these contexts, design science projects could be perceived as 'post-normal science' (Funtowicz and Ravetz 1993), which provides advice under conditions of uncertain facts and diverging values.

In the context of agricultural science and policies informing its goals, the maintenance of ecosystems and biodiversity is typically not presented as an intrinsic value, but in a rather utilitarian way with respect to the overarching values of prosperity and well-being (Haines-Young and Potschin 2010). The latter are described as depending on ecosystem services which are provided by intact and diverse ecosystems. The notion of ecosystem services implies an anthropocentric understanding of ecosystem function. Without these, it is feared, not only will productivity eventually break down, but other negative consequences, for instance regarding climate change, will ensue. In the context of these externally set values and goals, agricultural science aims to deliver technical norms that are hoped to mediate the demands of productivity and sustainability. With metagenomics approaches, ecosystem functions of soils become re-interpreted in terms of networks of genes available in the ecosystem and the metabolic pathways they sustain (Schloter et al. 2018). This then has consequences in turn for the way specific goals are formulated regarding possible achievements or fixes, and ultimately determines the kinds of interventions suggested.

\section{Situation assessment}

The assessment of situations in which the goals are relevant and that can be changed through intervention happens on a global and a local level. The growing demands for agricultural products and the degree of ecosystem degradation and biodiversity loss need to be determined on a global or national level such that 
recommendations can inform policies. Also, on the local level of the individual field, farmers need to make decisions regarding soil and crop management. Much research is thus focused on developing soil quality indicators. Metagenomics approaches are increasingly utilized for this purpose. Microbial indicators can be used to monitor the state of soils on larger scales or report on the state of a specific field, and it is hoped that degradation or biodiversity loss can not only be measured, but detected at early stages, allowing for mitigating actions (Schloter et al. 2018). While physical and chemical indicators are seen as equally valuable, microbial indicators are envisioned to replace other indicators where they are cheaper or easier to apply. Furthermore, such indicators could be highly specific such that they can measure the availability of specific ecosystem services in a given agroecosystem. sessment of situations and possible interventions. We are not suggesting that these fields are limited to a metagenomics approach and the associated theoretical perspective. Physical and chemical technologies for soil analysis are also used and further developed. Nonetheless, metagenomics approaches have oriented the outlook of agricultural soil microbiology strongly on a genome-centered notion of ecosystem services.

Our analysis suggests that this perspective tends to support instrumental attitudes towards sustainability. In extension to Niiniluoto's advice that in order to avoid short term "instrumental reason", focusing solely on economic or technical efficiency, "a technical norm should include among its antecedent A all the relevant valuations that concern the direct and indirect consequences of the recommended action X" (Niiniluoto 1993, p.16), it would be possible to suggest another meta-technical norm,

\section{Metagenomics approaches are increasingly utilized for developing soil quality indicators.}

\section{Intervention}

Technologies developed in basic research projects are sometimes developed further in design science projects as handles for interventions (e. g., DNA specific enzymes were developed into biotechnologies). Knowledge about microbiomes and metagenomics approaches qua indicators, instead, are mainly developed to evaluate practices and plan interventions involving other, often well-established technologies such as soil and crop management and the use of fertilizers and pesticides. For instance, much research has focused on how tillage and cropping regimes shape the microbiome and this line of design science has delivered specific technical norms concerning these practices (Bowles et al. 2016). Especially if reliable microbial indicators were turned into easy-to-use testing kits, farmers could make specific interventions based on these technologies, but concerning the use of other technologies. For instance, farmers could apply chemical amendments only when certain metagenomically defined microbial metabolic functions were found missing. Additionally, however, metagenomics knowledge and approaches can be a pre-condition for using microbes as technologies in microbial community engineering (Ke et al. 2020). Even if commercially produced microorganisms are available today for coating seeds before planting, much of the research remains promissory at this stage (Oviatt 2020).

\section{Conclusion}

We have shown how the introduction of NGS-based metagenomics has transformed the way microbial ecology describes ecosystems such as soil and how this in turn influences recommendations delivered by agricultural soil research regarding the as- i. e., a recommendation as to how to construct technical norms, based on our analysis: When developing or adopting technical norms, the directed and selective nature of approaches underlying the assessment of situations and delineation of causal relations should be taken into account and they should be considered and framed against the background of alternative approaches.

\section{Acknowledgements}

The research was funded by the Deutsche Forschungsgemeinschaft (DFG) 362545428

\section{References}

Ackert, Lloyd (2007): The "Cycle of Life" in ecology. Sergei Vinogradskii's soil microbiology, 1885-1940. In: Journal of the History of Biology 40 (1), pp. 109-145. https://doi.org/10.1007/s10739-006-9104-6

Berg, Gabriele et al. (2020): Microbiome definition re-visited. Old concepts and new challenges. In: Microbiome 8 (1), p.103. https://doi.org/10.1186/ s40168-020-00875-0

Bowles, Timothy; Jackson, Louise; Loeher, Malina; Cavagnaro, Timothy (2017): Ecological intensification and arbuscular mycorrhizas. A meta-analysis of tillage and cover crop effects. In: Journal of Applied Ecology 54 (6), pp. 1785-1793. https://doi.org/10.1111/1365-2664.12815

Desai, Narayan; Antonopoulos, Dion; Gilbert, Jack; Glass, Elizabeth; Meyer, Folker (2012): From genomics to metagenomics. In: Current Opinion in Biotechnology 23 (1), pp.72-76. https://doi.org/10.1016/j.copbio.2011.12.017

Fierer, Noah (2017): Embracing the unknown. Disentangling the complexities of the soil microbiome. In: Nature Reviews Microbiology 15 (10), pp. 579-590. https://doi.org/10.1038/nrmicro.2017.87

Fierer, Noah et al. (2012): Cross-biome metagenomic analyses of soil microbial communities and their functional attributes. In: Proceedings of the National Academy of Sciences National Academy of Sciences 109 (52), pp. 21390-21395. https://doi.org/10.1073/pnas.1215210110 
Funtowicz, Silvio; Ravetz, Jerome (1993): Science for the post-normal age. In: Futures 25 (7), pp. 739-755. https://doi.org/10.1016/0016-3287(93)90022-L Gibbons, Michael et al. (1994): The new production of knowledge. The dynamics of science and research in contemporary societies. London: SAGE Publications.

Gupta, Shashank et al. (2019): Amplicon sequencing provides more accurate microbiome information in healthy children compared to culturing. In: Communications Biology 2 (1), pp. 1-7. https://doi.org/10.1038/s42003-0190540-1

Haines-Young, Roy; Potschin-Young, Marion (2010): The links between biodiversity, ecosystem service and human well-being. In: David Raffaelli and Christopher Frid (eds.): Ecosystem ecology. A new synthesis. Cambridge, U. K.: Cambridge University Press, pp.110-139. https://doi.org/10.1017/ CB09780511750458.007

Ke, Jing; Wang, Bing; Yoshikuni, Yasuo (2020): Microbiome engineering. Synthetic biology of plant-associated microbiomes in sustainable agriculture. In: Trends in Biotechnology 39 (3), pp. 244-261. https://doi.org/10.1016/j. tibtech.2020.07.008

Konopka, Allan (2009): What is microbial community ecology? In: The ISME Journal 3 (11), pp. 1223-1230. https://doi.org/10.1038/ismej.2009.88

Kulkarni, Pranav; Frommolt, Peter (2017): Challenges in the setup of large-scale Next-Generation Sequencing analysis workflows. In: Computational and Structural Biotechnology Journal 15, pp. 471-477. https://doi.org/10.1016/j. csbj.2017.10.001

Lewis, William; Tahon, Guillaume; Geesink, Patricia; Sousa, Diana; Ettema, Thijs (2021): Innovations to culturing the uncultured microbial majority. In: Nature Reviews Microbiology 19, pp. 1-16. https://doi.org/10.1038/s41579020-00458-8

Martiny, Adam (2019): High proportions of bacteria are culturable across major biomes. In: The ISME Journal 13 (8), pp. 2125-2128. https://doi.org/10.1038/ S41396-019-0410-3

Massimi, Michela (2018): Four kinds of perspectival truth. In: Philosophy and Phenomenological Research 96 (2), pp. 342-359. https://doi.org/10.1111/ phpr.12300

Niiniluoto, Ilkka (1993): The aim and structure of applied research. In: Erkenntnis 38 (1), pp. 1-21. https://doi.org/10.1007/BF01129020

Noll, Samantha (2016): Agricultural science and values. In: Paul Thompson and David Kaplan (eds.): Encyclopedia of food and agricultural ethics. Dordrecht: Springer Netherlands, pp. 1-6. https://doi.org/10.1007/978-94-007-61674_564-1

O'Malley, Maureen (2014): Philosophy of microbiology. Cambridge, U. K.: Cambridge University Press.

Oviatt, Peter (2020): Soil drugs of the future. The sustainability of BioAg and the repair of arable land. In: Environment and Planning E: Nature and Space (online first). https://doi.org/10.1177/2514848620943894

Pace, Norman; Stahl, David; Lane, David; Olsen, Gary (1986): The analysis of natural microbial populations by ribosomal RNA sequences. In: Kevin Marshall (ed.): Advances in microbial ecology. Boston, MA: Springer US, pp. 1-55. https://doi.org/10.1007/978-1-4757-0611-6_1

Pereira, Rui.; Peplies, Jörg; Brettar, Ingrid; Höfle, Manfred (2017): Development of a genus-specific next generation sequencing approach for sensitive and quantitative determination of the Legionella microbiome in freshwater systems. In: BMC Microbiology 17, p. 79. https://doi.org/10.1186/s12866-0170987-5
Prosser, James (2020): Putting science back into microbial ecology. A question of approach. In: Philosophical Transactions of the Royal Society B: Biological Sciences, 375 (1798), p. 20190240 . https://doi.org/10.1098/rstb.2019.0240

Puig de la Bellacasa, Maria (2015): Making time for soil. Technoscientific futurity and the pace of care. In: Social Studies of Science 45 (5), pp. 691-716. https:// doi.org/10.1177/0306312715599851

Rheinberger, Hans-Jörg (1997): Toward a history of epistemic things. Synthesizing proteins in the test tube. Stanford, CA: Stanford University Press.

Schloter, Michael; Nannipieri, Paolo; Sørensen, Sфren; van Elsas, Jan (2018): Microbial indicators for soil quality. In: Biology and Fertility of Soils 54 (1), pp. 1-10. https://doi.org/10.1007/s00374-017-1248-3

Slatko, Barton; Gardner, Andrew; Ausubel, Frederick (2018): Overview of NextGeneration Sequencing technologies. In: Current Protocols in Molecular Biology 122 (1), p. e59. https://doi.org/10.1002/cpmb.59

Staley, James; Konopka, Allan (1985): Measurement of in situ activities of nonphotosynthetic microorganisms in aquatic and terrestrial habitats. In: Annual Review of Microbiology, 39 (1), pp. 321-346. https://doi.org/10.1146/annurev. mi.39.100185.001541

Stokes, Donald (1997): Pasteur's quadrant. Basic science and technological innovation. Washington, DC: Brookings Institution Press.

Thompson, Paul (2016): The many meanings of sustainability. A competing paradigms approach. In: Steven Moore (ed.): Pragmatic sustainability. Dispositions for critical adaptation. London: Routledge, pp. 16-28.

Woese, Carl; Gutell, Robin; Gupta, Ramesh; Noller, Harry (1983): Detailed analysis of the higher-order structure of 16S-like ribosomal ribonucleic acids. In: Microbiological Reviews 47 (4), pp. 621-669. https://doi.org/10.1128/ MR.47.4.621-669.1983

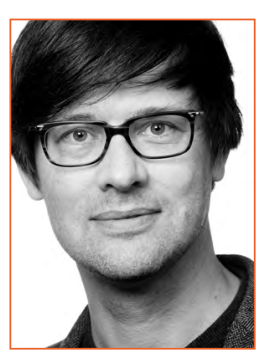

\section{DR. ROBERT MEUNIER}

is Principal Investigator of the DFG-funded project "Forms of Practice, Forms of Knowledge: Method, Notation and the Dynamics of Perspectives in the Life Sciences" (2018-21) at the Institute of Philosophy, University of Kassel. He works on the history and epistemology of the life sciences.

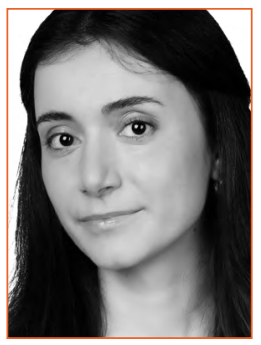

\section{SALIHA BAYIR}

is a PhD student in the DFG-funded project "Forms of Practice, Forms of Knowledge: Method, Notation and the Dynamics of Perspectives in the Life Sciences" (2018-21) since 2019. She has a dual background in life sciences and philosophy and works on the history and philosophy of microbial ecology. 